\title{
INTEGRATED MODEL OF DEMAND FOR TELEPHONE SERVICES IN TERMS OF MICROECONOMETRICS
}

Paweł Kaczmarczyk, Ph.D.

The State University of Applied Sciences in Płock

Faculty of Economics and Information Technology

Department of Economics

Nowe Trzepowo 55, 09-402 Płock, Poland

e-mail: p.kaczmarczyk@pwszplock.pl

Received 10 Decmber 2015, Accepted 16 November 2016

\begin{abstract}
The paper presents the results of the testing effectiveness of the integrated model in the short-term forecasting of demand for telephone services in 24-hour cycles. The linear regression model with dichotomous (binary) independent variables was integrated with the feed forward neural network. The regression model was used as a filter of modelled variability of the demand. The neural network was used to model residual variability. The research shows that the integrated model has a higher possibility of approximation and prediction in comparison to the non-integrated linear regression model. The research study was based on data provided by the selected telecommunications network operator. The range of empirical material consisted of hourly counted seconds of outgoing calls and generated by network subscribers in various analytical sections.
\end{abstract}

Keywords: Decision Support System, linear regression, feed forward neural network, forecasting

JEL classification: C45, C53, D24 


\section{Introduction}

The modelling and forecasting of the telecommunications market is an invariably actual subject of research. In connection with the initiative of the building of an Information Society, telecoms operators are functioning in an increasingly higher level of competition. This initiative was included in the Europe 2020 Strategy (Begg, 2010, pp. 146-151; European Commission 2010), which is a continuation and extension of the Lisbon Strategy (Lisbon European Council, 2000). The Lisbon Strategy already includes liberalization of the European Union electronic communications sector (i.e. the abolition of restrictions, monopolies and discrimination), and the development of An Information Society For All initiative as the first primary objective in the field of telecommunications. Harmonization of the UE telecommunications market was adopted as the second primary objective in the referenced strategy and analysis field. This means implementing common regulations to make the conditions fair for all telecommunications operators (e.g. in terms of connecting to the network). The execution of measures that led to achieving these objectives led to an increase in operator numbers and an increase in the competition level on the EU telecoms market.

Therefore, telecom operators want to improve decision-making processes, and they are also interested in the use of effective Decision Support Systems (DSS). DSS calls for carrying out the decision-making process based on rational procedures, which reduces the level of uncertainty. Extremely important in this context is the question of the forecasts accuracy of demand for telecommunications services. The quality of the decisions made by managerial staff and consequently maintaining at least the competitiveness and market position depend on the accuracy of these forecasts.

\section{The purpose and thesis of the research}

DSS, which is exclusively dedicated to formulating forecasts, is often called the Prediction Systems (PS) (Dittmann, 2004, pp. 180-207). In terms of literature, PS are therefore a specific subclass of the DSS. PS can function alone, or as a part of a broader (multifunction) DSS. DSS within the meaning of a broad system or specialized by definition PS, where algorithms of artificial intelligence (AI) are implemented, are called Intelligent Decision Support Systems (IDSS) or Intelligent Prediction Systems (IPS) (Kiełtyka, 2000, pp. 5-16).

In the literature of electronic communications, contents which relate to the modelling and forecasting of demand for telephone services are not popular. Moreover, there is a lack of such contents noticed in the effectiveness descriptions of the telecommunications market data mining 
techniques and methods (including econometric tools) practiced by operators. It is associated with the existence of significant competition between operators. Practically speaking, the transfer of knowledge does not exist in the field of telecommunications data mining, because operators are not interested in sharing their experiences as they treat the knowledge acquired by using data mining methods as a part of their competitive advantage (Muraszkiewicz, 2000, p. 27).

The analysis of the predictive capabilities, which are currently implemented in commercial Decision Support Systems (e.g. PROPHIKS, KOBAT-SAIR, KOBAT-SAD), encourages one to do research into other approaches of forecasting the demand for telephone services, and to assess their implementation techniques, including also the use of AI. According to Prof. M. Muraszkiewicz (2000, p. 27), commercial software to conduct data mining experiments is not always effective to solve tasks formulated by telecommunications operators, particularly, to solve problems where there are more complex data structures and temporal dependences (sequences of events).

The results of the research study, which are described in this paper, refer to one of the IPS components, i.e. the forecasting techniques using AI. The aim of this study is to verify the effectiveness of the integrated model in short-term forecasting of the demand for telephone services. A linear regression model, which includes dichotomous (binary) independent variables, was integrated with an artificial neural network model. A regression model is used as a filter of modelled variability of demand for telecommunications operator services. A neural network is used to capture the remaining (smaller) volatility of the demand for electronic communications services, i.e. received after the filtration of the origin variability of the modelled demand.

The author formulated the thesis, with regard to the approximation and prediction, integration of the above tools allows for better results in comparison to non-integrated linear regression models. A discussion of the comparable models effectiveness was based on the obtained values: fit coefficients, autocorrelation coefficients, partial autocorrelation coefficients, and the average errors of expired forecasts ex-post.

Research was carried out on the basis of data provided by one of the telecommunications network operators. The range of empirical material consisted of hourly counted seconds of outgoing calls generated by subscribers on particular days (e.g. working or non-working), categories of connections, and subscriber groups. 


\section{The theoretical basis of the integrated model conception}

Demand model specification for provided telephone services depends on the premised forecast horizon. Short-term forecasting should take into account quantitative changes, which can mean an increase or a decrease in variable values in accordance with previously detected regularity (e.g. a regression function). Short-term forecasting is associated with the omission possibility of qualitative changes, which must be included in long-term forecasting, i.e. the essential characteristics change of phenomenon which is expressed through the disappearance of previously observed regularity. Thus, the forecaster, who executes the long-term prediction, should take into account the change of functional relationships or the disappearance of old dependences and the appearance of new dependences. The first change is reflected in the changes in the estimation of structural parameters of the model, or in the changes of the regression function type, and the second change is expressed in the change of independent variables (Cieślak, 2004, pp. 25-26; Dittmann, 2004, p. 34).

In the case of the tested models (in the experimental part of the study), which are dedicated to short-term and mid-term forecasting, qualitative changes do not occur or occur in trace dimensions. Therefore, these changes in the forecasting process carried out for tests needs are omitted here. The construction of the model takes into account factors from the calendar: the type of day (typical working day, Saturday, Sunday, New Year's Day) and the hour of the day. Moreover, the category of connection (e.g. mobile networks, trunk call, and international call) and the type of subscribers (business and individual) were taken into account.

The models describing the course of demand for telecommunications services in the long (many years) period should include: changes in the number and structure of customers and their tendency to an increase in the use of telephone services or tendency to save, changes in the demand characteristics (e.g. disappearance of the earlier cycle of daily demand) and changes of power of demand dependence on other phenomena (Nadolny, 2011, pp. 70-108).

In the short-term forecasting, promotional techniques used by an operator may have an impact on the level of demand for telecommunications services (i.e. cheaper calls in set periods of time, free installations). An identification of the impact significance of such factors should be carried out during the preparation of the model.

In this paper the approach to the modelling of relationships between multiple variables was applied. The approach is based on the fusion of the results obtained with the use of two different techniques, i.e. a linear multiple regression one and an artificial neural network. The first one is used to capture the linear relationship between the response variable and explanatory variables, 
and the second one is used to model the residual values of the first model (Masters, 1993, pp. 50-60; Lula, 1999, pp. 129-132). This is shown in Figure 1.

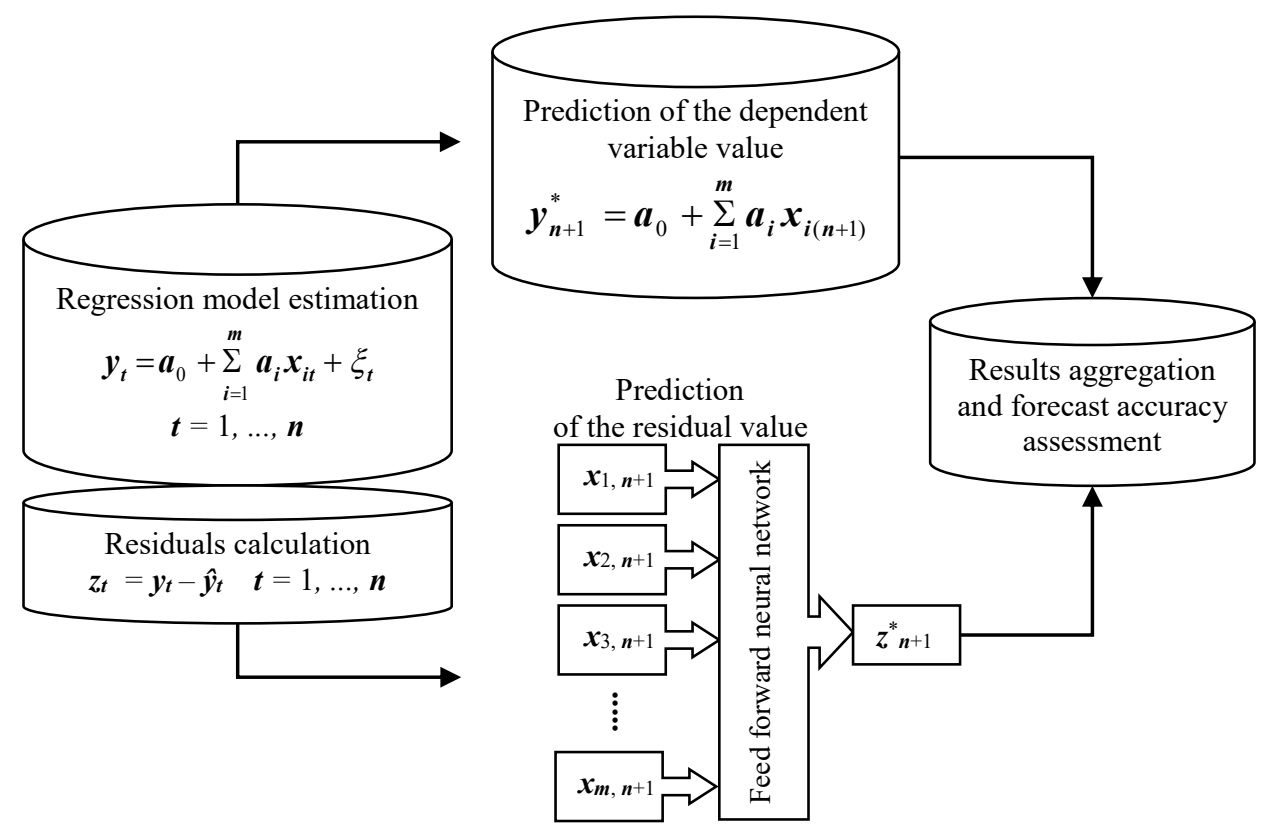

Figure 1. The integration of regression and neural network

Source: own explanation on the basis of T. Masters, Practical Neural Network Recipes in C ++ , Academic Press, Inc., San Diego 1993, p. 50-60.

The idea behind the application of a neural network for residuals modelling (regression model errors) is the desire to concentrate network capability on the non-linear approximation of subtle (small) variability. In this sense, the use of neural networks for full variability modelling is irrational. The ways of eliminating deterministic components are an important issue from the standpoint of prediction accuracy (Box, Jenkins, Reinsel, 1994; Makridakis, Wheelwright 1989; Makridakis, Wheelwright, Hyndman, 1998). The neural network model, with output considered as regression model residuals, is estimated like multiple regression, in a sense of the same inputs. 


\section{Estimation and assessment of models of demand for telecommunications services}

In the all of conducted analyses, the demand for telephone services (response variable) was measured hourly and the call time (sec.) of outgoing connections was combined. All levels of the applied classification factors (i.e. hour within 24 hours, type of 24 hours, connection category, and the kind of subscribers group) are shown in Table 1.

Table 1. The specification of all levels of applied classification factors

\begin{tabular}{|l|l|c|c|}
\hline Variable symbol & \multicolumn{1}{|c|}{ Variable name } & Variable symbol & Variable name \\
\hline BIZ & Business subscribers & 07AM & $07: 00: 00-08: 00: 00$ \\
\hline IND & Individual subscribers & 08AM & $08: 00: 00-09: 00: 00$ \\
\hline MN & Mobile networks & 09AM & $09: 00: 00-10: 00: 00$ \\
\hline LC & Local calls to the same network & $10 \mathrm{AM}$ & $10: 00: 00-11: 00: 00$ \\
\hline LCO & Local calls to other networks & $11 \mathrm{AM}$ & $11: 00: 00-12: 00: 00$ \\
\hline TC & Trunk calls & 12PM & $12: 00: 00-13: 00: 00$ \\
\hline IC & International calls & $01 \mathrm{PM}$ & $13: 00: 00-14: 00: 00$ \\
\hline OC & Other connections & $02 \mathrm{PM}$ & $14: 00: 00-15: 00: 00$ \\
\hline W & Working 24 hours & $04 \mathrm{PM}$ & $15: 00: 00-16: 00: 00$ \\
\hline SAT & Saturday & $05 \mathrm{PM}$ & $16: 00: 00-17: 00: 00$ \\
\hline SUN & Sunday & $06 \mathrm{PM}$ & $17: 00: 00-18: 00: 00$ \\
\hline 12AM & $00: 00: 00-01: 00: 00$ & $07 \mathrm{PM}$ & $18: 00: 00-19: 00: 00$ \\
\hline 01AM & $01: 00: 00-02: 00: 00$ & $08 \mathrm{PM}$ & $20: 00: 00-21: 00: 00: 00$ \\
\hline 02AM & $02: 00: 00-03: 00: 00$ & $09 \mathrm{PM}$ & $21: 00: 00-22: 00: 00$ \\
\hline 03AM & $03: 00: 00-04: 00: 00$ & $10 \mathrm{PM}$ & $22: 00: 00-23: 00: 00$ \\
\hline 04AM & $04: 00: 00-05: 00: 00$ & $11 \mathrm{PM}$ & $23: 00: 00-00: 00: 00$ \\
\hline 05AM & $05: 00: 00-06: 00: 00$ & & \\
\hline $06 \mathrm{AM}$ & $06: 00: 00-07: 00: 00$ & & \\
\hline
\end{tabular}

Source: own coverage.

Working 24 hours

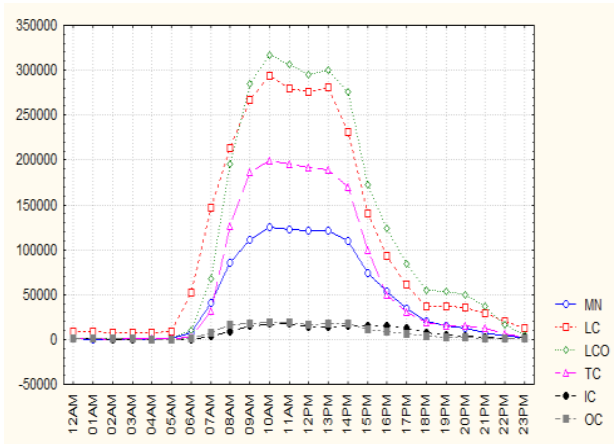

Sundays

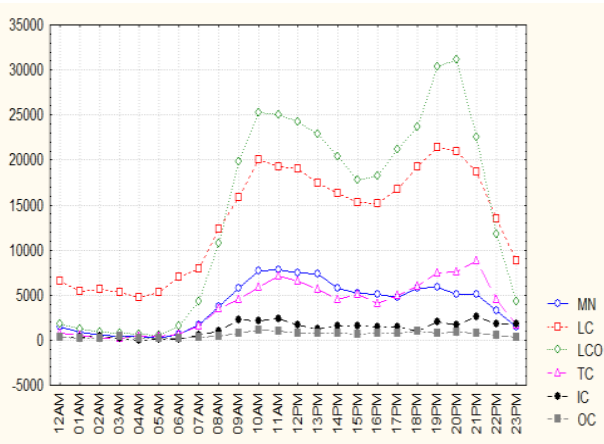

Figure 2. The average time (sec.) of outgoing calls generated by business customers in hours of working and non-working 24 hours

Source: own calculation. 
Working 24 hours
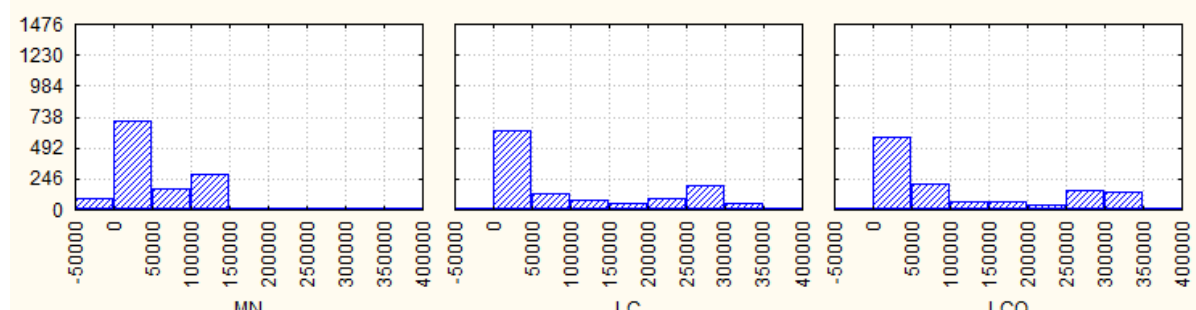

LC
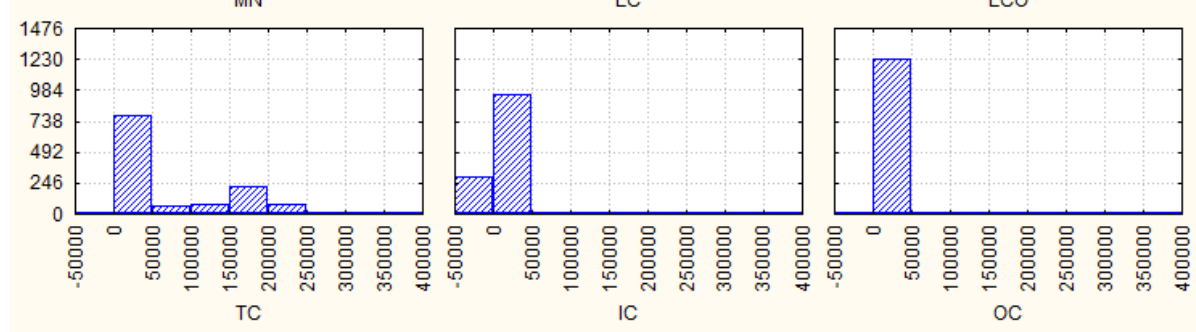

Sundays
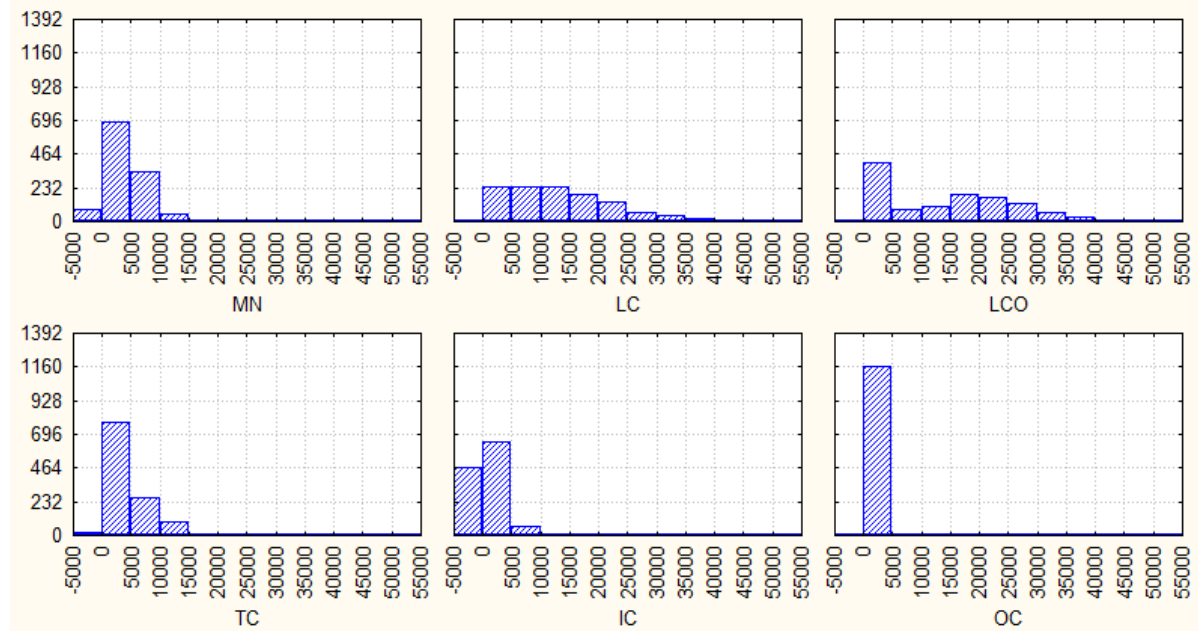

Figure 3. The structure of observations (hourly counted sec.) of outgoing calls generated by business customers during working and non-working 24 hours

Source: own calculation.

An exemplary daily course of the demand for telephone services, within the selected working 24 hours (Wednesdays) and generally non-working 24 hours (Sundays) in the period of a year and generated by business subscribers, is shown in Figure 2. The structure of demand observations (hourly counted seconds of outgoing calls) generated by business customers during working and non-working 24 hours (categorised histogram) is presented in Figure 3. 
As the result of a visual analysis it can be noticed that the variables distributions are different. The variable LCO has the highest values in both types of days.

In the regression model 35 dichotomous explanatory variables (they are specified in Table 1), that take the values 0 or 1, were applied. The Ridge regression model was estimated $(\lambda=0.0570)$. The value of the parameter $\lambda$ was optimized due to the best fit of the model to the data. Standard estimation was used. Model parameters were estimated from data for the period from 1st January to 20th February of the selected year (14,688 cases). Forecasts were verified in the period from 21 st to 28 th February (2,304 forecasts). The goodness of the regression model fit is shown in Table 2.

Table 2. Summary of the regression model

\begin{tabular}{|l|c|}
\hline \multicolumn{1}{|c|}{ Coefficient } & Value \\
\hline$\lambda$ & 0.0570 \\
\hline $\mathrm{R}$ & 0.6891 \\
\hline R Square & 0.4748 \\
\hline Adjusted R Square & 0.4736 \\
\hline $\mathrm{F}$ & 378.4818 \\
\hline $\mathrm{df}$ & $35 ; 14,652$ \\
\hline $\mathrm{p}$-value & 0.0000 \\
\hline Std. Error of the Estimate & 59524.1568 \\
\hline
\end{tabular}

Source: own calculations.

The only one of the structural parameters, namely the parameter standing by the variable 09PM, was statistically insignificant. The model assessment was supplemented by the analysis of autocorrelation and partial autocorrelation residuals. The results are shown in the next figure.

The autocorrelation function

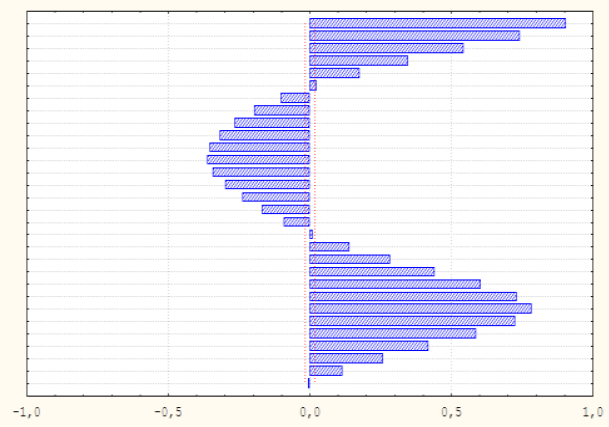

The partial autocorrelation function

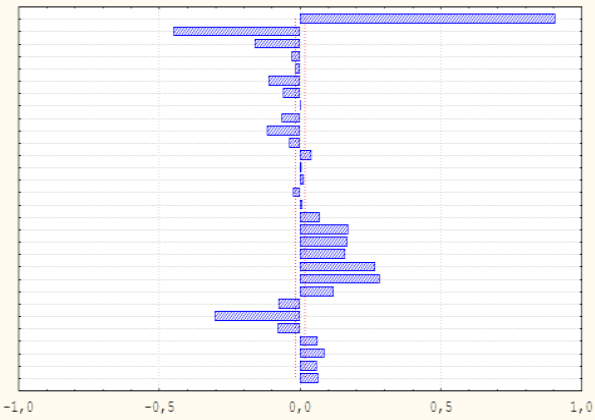

Figure 4. The autocorrelation function and the partial autocorrelation function of the regression model residuals

Source: own calculation. 
The values of the model residuals characterize with clear repetitions in 24-hour cycles. This is surely due to the diversity of the demand course in various analytical sections (in sections of: 24 hours, subscribers groups and connections categories), and too low model possibilities for reflecting such complex variability.

The forecasts accuracy was checked by using the following errors:

$$
\begin{aligned}
& M A E=\frac{1}{T-n} \sum_{t=n+1}^{T}\left|y_{t}-y_{t}^{*}\right| \quad-\text { mean absolute error, } \\
& R M S E=\sqrt{\frac{1}{T-n} \sum_{t=n+1}^{T}\left(y_{t}-y_{t}^{*}\right)^{2}}-\text { root mean square error. }
\end{aligned}
$$

$M A E$ and $R M S E$ (in sec.) for the forecast period amounted to 43148.92 and 57409.18 respectively.

In order to improve the efficiency of approximation and forecast accuracy, the integrated model was studied. In the learning process of the neural network, 35 dichotomous variables, the same as in the regression model case (Table 1), were used. However, the dependent variable was set by the obtained residuals of the regression model. The neural network model was estimated for the same time period as the regression model. The feed forward neural network with a logistic activation function of neurons was applied. The input layer consisted of 35 neurons and the output layer consisted of one neuron. The type of neural data representation one-of- $N$, which is characteristic for a nominal scale, was used.

In the learning process, an error back propagation algorithm was used. Weight updating was carried out after each presentation of a pattern from the training data set. During the neural network learning, the training patterns were mixed. The value of the learning coefficient was 0.9 , and the value of the momentum coefficient was 0.7 . Learning tolerance was set at 0.15 , and the testing tolerance at 0.25 . A bias coefficient was used. The probability of the learning algorithm stopping in a local minimum of error function in these experiments was reduced by using learning patterns mixing, the momentum coefficient, and also the multistart method. The level of RMSE of the testing set (15\% of the training set) was assumed as the selection criterion of the right neural network topology and the right weights values. The learning process was stopped when the RMSE value threshold of the testing set was reached. This error calculation was conducted after every learning epoch. The optimal neural network architecture was defined by using an empirical method. Then seven experiments were conducted, and each of them consisted of the decuple estimation of the neural model with a specified number of neurons in the hidden layer. These models had the following structures: 35-35-1, 35-30-1, 35-25-1, 35-20-1, 35-15-1, 35-10-1, and 35-5-1. In each experiment the best neural network 
was selected. Therefore, the next comparisons involved seven neural models. Finally, the best results of the learning process were obtained for neural network structure 35-20-1. This learning process is shown in Table 3.

Table 3. The learning process of neural network structure 35-20-1

\begin{tabular}{|c|c|c|c|c|c|}
\hline \multirow{2}{*}{$\varepsilon$ value } & \multirow{2}{*}{ Epoch } & \multicolumn{2}{|c|}{ Learning } & \multicolumn{2}{c|}{ Testing } \\
\cline { 3 - 6 } & & RMSE & out of tolerance & RMSE & out of tolerance \\
\hline 0.100 & 11 & 0.0993 & 1,854 & 0.0989 & 38 \\
\hline 0.090 & 2 & 0.0897 & 1,398 & 0.0837 & 5 \\
\hline 0.080 & 4 & 0.0810 & 1,183 & 0.0776 & 3 \\
\hline 0.070 & 12 & 0.0725 & 459 & 0.0662 & 0 \\
\hline 0.060 & 17 & 0.0618 & 354 & 0.0598 & 0 \\
\hline 0.055 & 19 & 0.0595 & 287 & 0.0540 & 0 \\
\hline 0.050 & 28 & 0.0529 & 157 & 0.0498 & 0 \\
\hline 0.045 & \multicolumn{7}{|l}{ It was not reach after caring out of 1000 epoch } \\
\hline
\end{tabular}

$\varepsilon$ value is the RMSE threshold of the testing set, below which the network learning process was stopped.

Source: own calculations.

Neural networks with small numbers of neurons in the hidden layer had poor learning outcomes. In contrast, network models that had too complex structures were characterized by a good fit to the training data and thus low capability to generalize (high testing RMSE values). The results of the integrated model analysis $(\mathrm{R}$ square $=0.7149)$ are shown in Figure 5.

The autocorrelation function

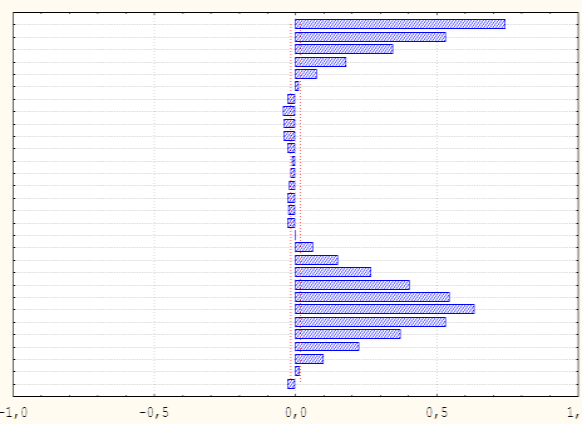

The partial autocorrelation function

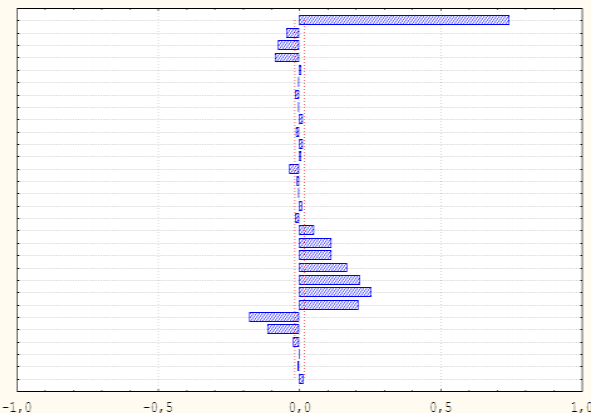

Figure 5. The autocorrelation function and the partial autocorrelation function of the integrated model residuals

Source: own calculation. 
The values of the Q Box and Ljung coefficients as well as partial correlation coefficients are much lower than in the case of the non-integrated regression model. They are of course not fully satisfactory but this creates opportunities for the verification of other solutions.

Then the forecasting effectiveness of the integrated model was verified. Average forecasting errors for the forecast period, accounted according to MAE and RMSE formulas, amounted to 14,412.19 and 22,708.22 respectively. The forecasting effectiveness of the integrated model was verified for the same time period as the forecasting effectiveness of the non-integrated regression. This was the objective basis for the comparison of the non-integrated model with the integrated model. Thus, forecasting errors are significantly lower (in the case of MAE even about three times lower) than the obtained forecasting errors by using the non-integrated regression model. This means that the forecast accuracy of the integrated model was much higher.

\section{Conclusions}

The integrated model provides a high efficiency of approximation and prediction of demand for telephone services in comparison with the non-integrated linear regression model.

The results provide rationales for further research in the explored field. The improvement of the fit and forecasts accuracy could be achieved probably by the separation of the information about the demand (particular days of the week, different months) as well as including different holidays within the year in analyses. Estimation of the regression model and neural model should be carried out on the basis of data for several years. The improvement of efficiency could be achieved also by verifying all possible refinements associated with the neural network technique. This concerns mainly the predictive procedures and the building of an optimal neural network model.

The models tested in this study, to formulate the short-and medium-term forecasts of demand for the services of a telecommunications company, are the basis for operational planning, which is one of the elements of planning policy in the company. Operational planning is used for the achievement of the objectives that are included in the company strategy. In operational planning the short and medium-term objectives and tasks of the company as well as the necessary means and conditions for their implementation are defined. Therefore, studies of the effectiveness of forecasting models are associated with the provision to the telecommunication company of a sound basis for price calculation, effective network management and the forecasting of demand for telecommunication services. As a result this leads to the strengthening of the market position (e.g. due to a more effective pricing policy) and increased profitability. 


\section{References}

Begg, I. (2010). Europe 2020 and employment. Intereconomics, 45, 146-151.

Box, G.E.P., Jenkins, G.M., Reinsel, G.C. (1994). Time Series Analysis. Forecasting and Control. Englewood Clifs: Prentice Hall.

Cieślak, B. (ed.) (2004). Prognozowanie gospodarcze. Metody i ich zastosowanie. Warszawa: Wydawnictwo Naukowe PWN.

Dittmann, P. (2004). Prognozowanie w przedsiębiorstwie. Metody i ich zastosowanie. Kraków: Oficyna Ekonomiczna.

Europe 2020. A strategy for smart, sustainable and inclusive growth. Communication from the Commission, European Commission. Brussels 3.3.2010. Downloaded from: http://www. buildup.eu/sites/default/files/content/ com2010_2020en01.pdf (accessed 22 July 2015).

Kiełtyka, L. (ed.) (2000). Inteligentny System Prognozowania, zasady funkcjonowania, zastosowania. Częstochowa: Wydawnictwo Politechniki Częstochowskiej.

Lula, P. (1999). Jednokierunkowe sieci neuronowe w modelowaniu zjawisk ekonomicznych. Kraków: Wydawnictwo Akademii Ekonomicznej w Krakowie.

Makridakis, S., Wheelwright, S.C. (1989). Forecasting Methods for Management. New York: J. Wiley.

Makridakis, S., Wheelwright, S.C., Hyndman, R.J. (1998). Forecasting Methods and Applications. New York: J. Wiley.

Masters, T. (1993). Practical Neural Network Recipes in C++. San Diego: Academic Press, Inc.

Muraszkiewicz, M. (2000). Eksploracja danych dla telekomunikacji. Downloaded from: http:// www.ploug.org. pl/showhtml.php?file=konf_00/materialy_00 (accessed 2 July 2015).

Nadolny, M. (2011). Podstawowe modele dyfuzji dóbr telekomunikacyjnych. In: J. Łyka (ed.), Wybrane modele matematyczne w ekonomii. Globalizacja i rozwój (pp. 70-108). Wrocław: Wydawnictwo Uniwersytetu Ekonomicznego.

Presidency Conclusions. Lisbon European Council of 23rd and 24th March 2000. Downloaded from: http://www.europarl.europa.eu/summits/lis1_en.htm (accessed 24 Jun 2015). 